Studia Anglica Posnaniensia 50/2-3, 2015

doi: $10.1515 /$ stap-2015-0030

\title{
THE SELF LOST, THE SELF ADJUSTED: FORMING A NEW IDENTITY IN BEREAVEMENT MEMOIRS BY AMERICAN WOMEN
}

\author{
KATARZYNA MAŁECKA
}

University of Social Sciences, Łódź

\begin{abstract}
Most Western cultures place a great value on autonomy. American society in particular has always stressed the need to succeed via self-reliance, a characteristic which, in recent decades, has additionally manifested itself in an increasing inclination for self-examination reflected in the deluge of autobiographical writing, especially memoirs. This analysis focuses on memoirs of spousal loss, a specific subgenre of life writing in which, due to the loss of a loved one, the narrating self realizes how unstable a sense of autonomy is. In their bereavement narratives, Joan Didion, Anne Roiphe, and Joyce Carol Oates admit that after losing a life partner their world crumbled and so did their sense of self. The article examines the following aspects of the grieving self: 1 . how grief tests one's self-sufficiency; 2 . how various grief reactions contribute to self-disintegration; 3 . the widow as a new and undesirable identity; and 4 . writing as a way of regaining one's sense of self.
\end{abstract}

Keywords: self, loss, widow, bereavement, memoir, independence, grief, writing, narrative, self-pity

\section{Introduction}

In the Introduction to Continuing bonds: New understanding of grief (1996), Phyllis R. Silverman and Dennis Klass comment on the importance of human relatedness:

To insist on a separateness that keeps very clear boundaries between people requires a mechanistic view of human functioning that fails to appreciate the importance of connection and relationship. Separateness predominates in modern Western cultures. The myth of rugged individualism associated with the United States and the concept of individuality that played itself out in the development of the western 
frontier springs from the same modern understanding of self - in spite of the actual historical situation on the frontier, which was one of cooperation and communal ties. (1996: 15)

Yet, in spite of historical evidence, the myths of "rugged individualism" and the self-made man persist. Independence and self-assurance are said to be the cornerstones of success in life, creating the image one projects in order to be reckoned with and noticed. Ironically, very few consider the fact that for this image to exist and matter others must be involved. American society in particular has always stressed the need to succeed via self-reliance, a characteristic which, in recent decades, has additionally manifested itself in an increasing inclination for self-examination reflected in the deluge of autobiographical writing, especially memoirs. This analysis focuses on memoirs of spousal loss, a specific subgenre of life writing in which, due to the loss of a loved one, the narrating self realizes how unstable a sense of autonomy is. In their respective bereavement narratives, Joan Didion, Joyce Carol Oates, and Anne Roiphe admit that after losing a life partner their world crumbled and so did their sense of self. The changes and readjustments after an important loss constitute some of the most challenging life experiences for which most of us are inadequately prepared. I look at four aspects which the memoirists address: 1 . how self-sufficiency often loses its appeal when tested by grief; 2. how shock, denial, and other grief reactions contribute to self-disintegration; 3 . the widow as a new and undesirable self; and 4. writing as a confirmed means of regaining one's sense of self. The memoirs under discussion are The Year of Magical Thinking (2005) by Joan Didion, Epilogue: A Memoir (2008) by Anne Roiphe, and A Widow's Story: A Memoir (2011) by Joyce Carol Oates.

\section{Grief-triggered awareness of the self's relationality}

In How our lives become stories: Making selves, Paul John Eakin devotes chapter two, "Relational selves, relational lives: Autobiography and the myth of autonomy," to a discussion on how life narratives appear to sustain, yet, in fact, many of them revise the concept of self-reliance and self-made identity (1999: 43-98). Eakin observes that while "autobiography promotes an illusion of self-determination: I write my story; I say who I am; I create my self," most life stories display relational identities, an issue that autobiography criticism failed to address properly until recently (1999: 43-44). Drawing on Carolyn Kay Steedman's Landscape for a good woman and theories of relationality and recognition by, among others, Nancy K. Miller, Susanna Egan, and Jessica Benjamin, Eakin challenges the model of the individualistic autobiographical self and replaces it with the notion of self which fluctuates between autonomy and interpersonality (1999: $45,49-57,68)$. 
Grief memoirists and modern bereavement theories contribute to the discussion of relational self in a comprehensive manner, responding to Eakin's appeal for more narratives exploring "relational selves living relational lives" to be written and analysed (1999: 55). With death, the bonds between the living and the dead do not necessarily become weaker, and the bereaved often realize their illusory independence fully only after a profound loss. Professional grief literature has been addressing this issue since Freud's speculations on the nature of the mourner's attachment to the deceased in "Mourning and melancholia." For instance, in their revised classic study on bereavement in adult life, Colin Murray Parkes and Holly G. Prigerson quote John Donne's memorable line "any man's death diminishes me" (2010: 111), stressing that literary perspectives on the loss of self with the death of the other precede and find confirmation in clinical research. Although "it is more comfortable to think about the self as a separate, independent, and therefore safe, entity," Parkes and Prigerson state, "people we love seem to become part of our self" and most boundaries we erect around ourselves to secure our identity are easily "permeable" (2010: 111). Modern bereavement theories do not favour Freud's guidelines according to which grief work should be completed (see Klass, Silverman and Nickman 1996), yet his main premise that we lose a part of ourselves when we lose the object of our affections still inspires researchers, who re-label the loss of the ego as the loss of one's "sense of self" or "identity" (see e. g. Parkes and Prigerson 2010: 110-111; Rando 1991: 26-28, 238-239; Silverman 2005: 55, 56, 63). According to Freud, when the object possesses "this great significance for the ego - a significance reinforced by a thousand links - then its loss will (...) be of a kind to cause either mourning or melancholia" ([1917] 1968: 256). Didion, Roiphe, and Oates represent independent and accomplished women who, after the loss of a spouse, discover that, paradoxically, much of their independence, in fact, depended on such reinforced links and attachments. This section explores the grieving self's sense of loss and growing awareness of incompleteness and relationality in the three memoirs.

Obsessed since childhood with finding meaning in life via reading and studying, in the aftermath of her husband's death, Joan Didion admits she found "equal meaning in the repeated rituals of domestic life," "in the intensely personal nature of [her] life as a wife and mother" ([2005] 2007: 190, 191). While this must have been known to her when her husband was alive, the sudden clarity of how much she depended on John dawns on her only after the loss:

[T]he survivors of a death are truly left alone. The connections that made up their life - both the deep connections and the apparently (until they are broken) insignificant connections - have all vanished. John and I were married for forty years. During all but the first five months of our marriage (...) we both worked at home. We were together twenty-four hours a day (...). I could not count the times during the average day when something would come up that I needed to tell him. This impulse did not end with his death. ([2005] 2007: 193-194). 
According to researchers, there is no such thing as "insignificant connections," and what Didion succinctly verbalizes here is her own take on attachment theory which has been developed and formulated by many specialists for over a century. Considered the father of attachment theory, British psychologist and psychiatrist John Bowlby studied and described the patterns of attachment behaviour between infants and their mothers. After extensive research, Bowlby concluded that "attachment behaviour in adult life is a straightforward continuation of attachment behaviour in childhood" (Bowlby [1969] 1982: 208). "In sickness and calamity," Bowlby states, "adults often become demanding of others; in conditions of sudden danger or disaster a person will almost certainly seek proximity to another known and trusted person" ([1969] 1982: 208). Thus, Bowlby stresses, it is fallacious to apply epithets such as "regressive," "undesirable," or "pathological" to adult manifestations of increased attachment because it plays a "vital role (...) in the life of man from the cradle to the grave" (Bowlby [1969] 1982: 208). Unfortunately, as Didion remarks, in adult life we often do not realize how vital for our well-being and integrity all kinds, even the most insignificant, of attachments are. Individuality and separateness predominate in increasingly secularizing Western cultures, and when a real crisis occurs in an individual's personal life we are surprised by emotions and impulses which go back to childhood, when our basic needs to be hugged, to cry, and to search for and find the proximity of others must be fulfilled because they are necessary for us to survive (see Parkes and Prigerson 2010: 48). Death severs all attachments for the dead, and, to a great extent, for the living, who, as Didion observes, are often unwilling to let these established connections go and often hold on to them for an extended period of time. In Didion's case, her magical thinking, a belief that her husband would come back, lasted for at least a year, considerably protecting her sense of identity. For a year, she continued to "seek proximity to another known and trusted person," in this case her dead husband, a behaviour which may be considered by some as a sign of pathological co-dependence, but, in fact, turns out to be natural and necessary for the further existence of the self.

The extent to which Didion might not have fully realized her own co-dependence with her spouse, even though she admits it in her memoir, reveals itself in a 2011 interview, in which the writer, asked if she has read any bereavement memoirs since her own was published, responds: "I read Joyce Carol Oates's [A Widow's Story] and I thought it was extraordinary. I know her slightly. I have never met anyone who was more dependent on the relationship in a marriage than Joyce and her husband were on each other" (Cross 2011: 49). A careful reading of Didion's account, however, prompts one to comment on her assessment of Oates's memoir by simply saying "it takes one to know one" - a generalization, maybe, but as Julian Barnes (2011) observes in his comparative article of the two memoirs, "Didion is essayistic and concise, seeking external points of comparison, 
trying to set her case in some wider context," which is exactly what she inadvertently does reflecting upon Oates's co-dependent union with her husband. The need to be able to reassert our independence seems to prevent us from remembering moments of great vulnerability and self-doubt. Eight years after her husband's death, Didion feels comfortable enough to comment on a state she had to cope with, failing to acknowledge that one-third through her memoir, unable to handle the pain of separation, she remarks, stifling an outburst of despair: "I wanted more than a night of memories and sighs. I wanted to scream. I wanted him back" ([2005] 2007: 75).

Although Didion attempts to underplay her dependence on her husband in the interview, in her "essayistic" memoir the orphaned self comes forward several times, making her account an interesting study of grief and its influence on the self. In contrast to Didion, Oates is, indeed, more "novelistic and expansive" (Barnes 2011). Her sense of being lost is reflected in the way she switches "between first and third persons" as well as in her focus on "the psycho-chaos of grief" (Barnes 2011), which, at times, echoes the mourning behaviour patterns of Edgar Allan Poe's Roderick Usher, whose co-dependent relationship with his sister leaves his life and house in ruins. On the first page of her memoir, Oates stresses how, with an important loss, the assumptive world crumbles and meaning-making ability diminishes: "My husband died, my life collapsed" ([2011] 2012: 1). Oates is a text-book example of Freud's model of bereavement described in "Mourning and melancholia" ([1917] 1968). Her emotional as well as intellectual investment in her dead spouse is repeatedly proclaimed throughout her over 400-page narrative:

You made my life possible. I owe my life to you (...). My loss is compounded by the unusual fact that Ray and I had no correspondence - not ever (...). [F]or we'd rarely been apart more than a night at a time (...); [I]t seems to us, who have "survived," that some part of us has died with those we'd loved, and is interred with them, or burnt to ash. [W]ithout Ray, there doesn't seem much point to anything I do. (Oates [2011] 2012: 74, 139, 233, 209, 269)

According to Therese Rando (1991: 28), a leading expert in grief counselling, after people "lose someone integral to themselves and their lives" they often are unable to continue normal life for a while, or even for an extended period of time, because such a loss triggers intense "identity confusion," undefined anxiety, and insecurity. People feel lost and insecure because they become increasingly aware that with the major loss they have also experienced multiple secondary losses, most importantly the loss of parts of their identity validated by the relationship they had (Rando 1991: 28). Thus, one grieves not only for the dead but also for oneself (Rando 1991: 28), which initially confuses Oates and makes her doubt any possibility of rebuilding a life without her husband in it (Oates [2011] 2012: 142). 
Less dramatically than Oates, Anne Roiphe observes how the permanent physical separation disturbs her sense of independence:

\begin{abstract}
And so I am alone. Not really all alone. My children are a phone call away. Friends are near and available if I need them. But I am mateless and that changes everything. I have always, all through our marriage, been a writer, a professional woman who might lunch with an editor, breakfast with an agent, have appointments to keep, a destiny of my own, separate from H.'s, separate from my children, a place in my head where I had my own thoughts and obligations. But I overestimated my independence. I now suspect it was never there at all. When I'm alone without a destination, a friend to meet for lunch or dinner, the hours drag on (...). I am not here if no one sees or hears me. Like the proverbial tree in the forest I neither fall nor stand unobserved. But I am observing myself and that should be enough. It isn't. (2008: 13-14)
\end{abstract}

Herman Roiphe, Roiphe's husband of nearly forty years, died unexpectedly when she was almost seventy. Like Didion and Oates, she was close to her husband, even though he worked outside the home (he was a psychoanalyst specializing in children's sexual identity). At the beginning of her memoir, Roiphe informs us that her account is going to be mostly about "the remaking of life" (2008: 4), but, as she quickly admits, the division between the former self and the grieving self is blurry, making "the remaking of life" challenging (2008: 4). She compares her grief to "a river that finally runs into the ocean where it is absorbed but not dissolved" and from which, one day, maybe a new life/self may emerge (2008: 4). The analogy with the ocean dictates the rhythm of the narrative, and Roiphe's observations about changes in her assumptive world view and her "unobserved" self come in waves, interspersed with her attempts to meet new men and rebuild her life. This, however, increases and confirms Roiphe's suspicion that her former independence was "overestimated" or even non-existent in the first place. Like Didion and Oates, in the aftermath of the loss, she painfully experiences the paradox Jessica Benjamin explores in The bonds of love: "at the very moment of realizing our own independence, we are dependent upon another to recognize it. At the very moment we come to understand the meaning of 'I, myself,' we are forced to see the limitations of that self" (1988: 33).

\title{
Grief experience and the self
}

In Reading Autobiography, drawing on Joan W. Scott's essay "Experience," Sidonie Smith and Julia Watson discuss how all experience, contrary to what the narrating self may believe, is never isolated, individual, or original (2001: 24-26). Once again, while most Western cultures promote the uniqueness of the self and its achievements, meaningful experience, embodied in the self, is always relational, based in cultural, social, and personal contexts. We would not know who 
we are and what our reactions to a given situation may or should be, if there was no reference frame of what various experiences mean for our well-being. However, there are experiences that seem to escape most discourses. Smith and Watson observe:

\begin{abstract}
At the same time that we say that experience is discursive, we recognize that there are human experiences outside discursive narratives - feelings of the body, feelings of spirituality, powerful sensory memories of events and images (...). Bodies bleed. They manifest illnesses. They get hurt. They feel hunger, thirst, and desire. These are among the material events in our lives. (2001: 26)
\end{abstract}

Feelings of the body and mind create the biggest illusion of individuality, and naturally so. When we are in pain, be it physical or psychological, what matters for most individuals is how to get rid of the pain, often perceived as exceptional and powerful, and become the former, less troubled, and socially adjusted self. But as Smith and Watson point out, the physicality of the body exists "literally as well as discursively" (2001: 26). Whenever we try to explain to a doctor what is wrong with us, express love and happiness to our loved ones, or need to be left alone with our suffering, we look for means and reasons to do so, which involves meaning-making, even if only to our own selves, via language and narrative (cf. Smith and Watson 2001: 25-26). Thus, even on the most intimate, physical level, "we retrospectively make experience and convey a sense of it to others through storytelling; and as we tell our stories discursive patterns guide, or compel, us to tell stories about ourselves in particular ways" (Smith and Watson 2001: 26).

In grief, powerful sensory experiences caused by loss often situate the suffering self closer to the body and mind. Grief connects the self to reactions that are natural and culturally recognizable, yet not always understood or accepted, as well as isolates the self from the social and discursive. Sometimes, the self sustains such isolation, veering away from the social bonds that offer restoration and adjustment, which may result in complicated grief demanding special treatment. In most bereavement memoirs, the self's grief reactions are described in a consistent manner - they are person-specific but common patterns emerge, connecting the grieving self, separated as it temporarily is, to discursive patterns explored in professional bereavement literature. In other words, the way the grieving self responds to a loss inadvertently guides it out of its isolation toward a wider context, if only by telling stories which more often than not coincide with other existing bereavement records.

The narratives by Didion, Roiphe, and Oates testify to the commonness of certain grief reactions, situating the detached, bereft self in relation to other bereft selves within and without the narratives (all three writers compare their experience to that of other widowed individuals they meet or hear/read about in the course of their story; the external perspective is provided by readers and critics, 
who often compare the three memoirists to each other as well as to other accounts of grief). Even if each of the memoirists cannot see beyond their grief-stricken self for a time, they all recognize their unsought isolation, which, in turn, compels them to observe their separate self to provide it with a semblance of recognition and secure its survival. Based on the records Didion, Roiphe, and Oates present, and taking into account that the death of a loved one features as number one on most life-stress inventories, recounting grief experience in a memoir can be as harrowing for the autobiographical subject as the experience itself. With a significant loss, a whole range of emotions, beliefs, memories, and other private and social aspects of the self become naturally disturbed. Emotions and behavioural, cognitive, and somatic effects include: shock, disbelief, denial, anger, fear, acute loneliness, anxiety, guilt, self-punishment, chest pains, heart palpitations, lack of energy, hallucinations, appetite disturbances, seclusion, avoiding reminders of the deceased, and many more (see e. g. Parkes and Prigerson 2010: 24, 90-96, 100, 111; Raphael 1985: 30, 39; Worden 2009: 18, 20, 23-24). Given this still incomplete list of grief's major side-effects, one wonders how the grieving self survives at all and then recovers to tell the tale. Fortunately, our less conscious self knows what to do and triggers shock and denial/disbelief, the most common first reactions to a loss, to protect the self from the initial pain and disintegration (Kübler-Ross and Kessler 2007: 8, 10). Shock and denial play an important part not only at the beginning of bereavement. In some cases, these sheltering emotions last longer than a week or even a month, making survival possible for those who find their loss exceptionally difficult to endure and cope with. Of course, in grief nothing is simple, and sometimes shock and denial also increase the feeling of being lost, altering the self for some time or even forever.

Anne Roiphe stresses the beneficial effect of shock, without which, she says, she feels "exposed," as if she was "a mollusk without a shell, a formless thing, veins showing, trembling naked on a rock" $(2008: 11,12)$. Then, recollecting the funeral, Roiphe observes how shock protects as well as blurs a sense of self:

\footnotetext{
I didn't flood with tears when we stood by the open grave. I was too shocked, too numb, and besides I wasn't sad, it seemed as if someone were operating on me and I was awake. I was without pain but without volition, without self. (2008: 24)
}

Roiphe's description captures the vulnerability of the self in the early stages of grief. The absence of her husband poses a situation she has no skills to deal with at the moment, so the feeling of being lost, "without volition," as if unconscious or barely alive, becomes a coping mechanism to gradually adapt the self to what has happened and what may come. The limbo state Roiphe experiences has been widely described in grief literature, yet, in contrast to Freud's understanding of how grief work needs to be completed, modern grief theories do not rush the 
bereaved to abandon the state of shock and sever the bonds with the dead. The transition should be gradual and the self is allowed to oscillate between hanging onto the lost object and forming new attachments (see Klass, Silverman and Nickman, 1996; Stroebe and Schut, 2010). The pain of separation replaces the state of shock in waves, which Roiphe also acknowledges and welcomes, sensing that the self needs the ebb and flow of this pain to realize it is depleted yet still alive (cf. Roiphe 2008: 4).

Didion's grief reactions also confirm the self's natural need to hang onto disbelief and the deceased, even though, relying on Freud's conception of grief as illness, she diagnoses herself as "incapable of thinking rationally" and, thus, ill, only because she catches herself believing John may come back (Didion [2005] 2007: 34-35, 37). When her husband suddenly died at their dinner table, Didion remembers acting in a robot-like manner ([2005] 2007: 28). Her initial shock morphs into long-lasting denial, a state which she is able to recognize but unable to shake off. The night of the death she believed that on some level "what happened was reversible" (Didion [2005] 2007: 32). This false reasoning of the grieving self continues longer and more intensely than Didion initially realizes:

$[T]$ hrough the winter and spring there had been occasions on which I was incapable of thinking rationally. I was thinking as small children think, as if my thoughts or wishes had the power to reverse the narrative, change the outcome. In my case this disordered thinking had been covert, noticed I think by no one else, hidden even from me, but it had also been, in retrospect, both urgent and constant. ([2005] 2007: 35)

Didion's fact-obsessed self is unable to keep in check the belief in the power of thought to shape reality, which plays tricks on her until almost a year later when she reads the results of the autopsy. Her disbelief, exhibited in the title magical thinking, puts Didion's logical self on hold, preventing her from fully accessing the realization that her husband will not come back. In Totem and taboo, Freud describes the phenomenon of magical thinking, drawing comparisons between certain primitive cultures which believe "in the omnipotence of thought (...) to dominate the world" and the attitude to life often exhibited by neurotics (Freud [1918] 2009: 116-117). Neither of these behaviours allows the conscious, knowledgeable self to realize what its "real place in the world" is (Freud [1918] 2009: 116-117), causing delusions and distortions in the perception of the world and oneself. While such disturbances may be acceptable within a given culture or among little children, and, in the case of many neurotics are predominantly harmless, a person like Didion, whose whole life has been devoted to a search for information and knowledge, questions the judgment of her bereaved constitution, even though the source of her behaviour fully justifies acting in a less day-to-day manner for longer than a day or two. 
Jeffrey Berman, an autobiography scholar and grief memoirist, points out that, "unlike other memoirs about deceased spouses," Didion's best-selling account provides very little information about her husband and their marriage (2010: 158). Berman also implies that whatever little information we get about the relationship seems whitewashed (2010: 158). Examining the veracity of personal interactions between the autobiographical subject and other living individuals is beyond the focus of this analysis. It needs to be stressed, however, that Didion's account became an instantaneous bestseller not because the subject matter is overly romantic or full of sensational disclosures, but because her grief experience parallels professional grief records and appears to be hardly mediated by the autobiographical self, which apparently appealed to many readers. Declarations of love or marital problems may not be elaborated upon in Didion's memoir, although several intimate moments are shared, but the pain caused by the termination of what was undoubtedly a profound union is pronounced on each page of the book, evoking empathy for the self that, unattached and aging, is struggling to make sense of life, death, marriage, memory, grief, and "the ways in which people do and do not deal with the fact that life ends" (Didion [2005] 2007: 7-8).

While Roiphe and Didion oscillate between shock, denial, despair, gradual adjustment to loneliness, and attempts to seek recognition for the self in new social engagements, duties, and family obligations, Joyce Carol Oates's grief-induced anger, self-reproach, and desolation obliterate her almost completely. In "Mourning and melancholia," Freud states that "[t]he melancholic displays something else besides which is lacking in mourning - an extraordinary diminution in his self-regard, an impoverishment of his ego on a grand scale" (Freud 246). Oates suffers from grief-related suicidal depression, and her lowered self-esteem and self-punishment, resulting from survivor's guilt, match all the conjectures proposed by Freud:

$[\mathrm{M}] \mathrm{y}$ "self" is a swirl of atoms not unlike the more disintegrated paintings of J. M.
W. Turner (...). I am obsessed with my "self" now - whatever it is, it seems to be
about to break and be scattered by the wind, like milkweed pollen (...). "Joyce
Carol Oates" doesn't exist, except as an author-identification (...). This is not a
person. This is not a life (...). I am not a writer now. I am not anything now. Legally
I am a "widow" (..). But beyond that - I am not sure that I exist (...). The truth
is, it was I - the wife, the widow - who left my husband behind (...). Outliving your
husband is a low vile vulgar thing and you do not deserve to live an hour longer
(...). Your punishment is to be yourself: widow. This is a just punishment. ([2011]
2012: $127,128,170,243,200,264)$.

The italicized sections stand for Oates's hallucinations in which she sees, in the corner of her eye, "The Basilisk," "the lizard-like creature" lurking in different parts of the house, staring at her from time to time, and evoking self-punishing and suicidal thoughts ([2011] 2012: 128, 169, 200, 213). Some other sections are 
italicized when Oates refers to herself as "the Widow" and discusses "the Widow's" fate in the third person. The grieving writer/former wife becomes progressively more and more perturbed and concerned about how she feels and who she is. Halfway through the narrative she evaluates her condition resignedly: "[H]ow desperate, how frantic, how unrecognizable to myself I really am" ([2011] 2012: 231). And yet, among this confusion, Oates senses a way to save the disintegrating self. As she imagines "the Basilisk," the id-like manifestation of her guilt, and depersonalizes herself as the morbid "Widow," the narrating subject creates a persona which, "unrecognizable" to herself as she is, monitors the unflinching pain and remorse not to let the " $P$ " disappear entirely. Gail Godwin, one of Oates friends, intuitively assesses this saving power of acute grief, comforting the distraught writer in a candid, if harsh, manner: "Suffer, Joyce. Ray was worth it" ([2011] 2012: 119, 197, 198). And so she does, for nearly 400 intense pages. On the last one, the suffering self arrives at the threshold of adjustment, announcing her accomplishment in a form of advice to other widowed selves: "on the first anniversary of her husband's death the widow should think $I$ kept myself alive" ([2011] 2012: 416; emphasis in the original). At first, this may sound as a confirmation of the myth of individuality, a proud confession, a courageous act completed with no help from the outside: " $P$ " kept "myself" alive. Indeed, the loneliness of the grieving self is most striking in Oates's memoir, but the sentiment here is hardly self-laudatory. The statement results from the realization that grief is not over (the widow is still alone) yet one can live with or next to the turmoil it inflicts, especially when others support the widow in her compulsion to grieve, without hastening her through this meaningful process. The advice and comforting words Oates receives from Godwin and other people via phone and email exchanges (the memoir is interspersed with multiple "E-mail records") testify to how crucial even such detached social responsiveness is to the grieving self who seems to think it is better off if left alone with its pain. In her concluding statement, Oates's bereaved autobiographical "I" has adjusted, at least partially, to the state of widowhood (the word widow ceases to be capitalized). The insistence on referring to herself in the third person suggests not so much depersonalization any more as the materialization of a new identity that complements "Joyce Carol Oates."

Freud was correct in assessing the basic symptoms of grief experience and comparing them to those of a melancholic. What he was mistaken about, and failed to practice himself after the deaths of his grandson and daughter, is the necessity of detaching the grieving self from the deceased (see Klass, Silverman and Nickman 1996: 6-7, 12-13). The suffering inflicted by grief is something the self wants to relinquish as well as needs to hold onto. Shock and denial help the self not to disintegrate at the time of acute grief. When these emotions subside, the bereaved move on at their own pace, often sustaining long-lasting bonds with 
the deceased through memories, both oral and written, as well as through the happiness and/or pain such recollections may cause, which provides at least a semblance of identity to the diminished self. The patterns of grief experience, illusions and identification with the dead, words of wisdom from friends, and attempts to tell the story of bereavement situate the bereft self within a complex weave of relationships, securing its survival and gradual adjustment to life after loss.

\section{The widow: The self no one wants to be}

Addressing herself as "the Widow," yet not really sure who "the Widow" is and what is expected of her, Oates touches upon an important personal and social issue - the state of widowhood - a label that many grieving women resist. On the one hand, becoming a widow confirms one's continued existence; on the other, the degradation from the role of wife to the status of widow greatly contributes to one's identity confusion, demonstrating yet again the self's innate dependence on interpersonal bonds. If you lose your life partner, you lose that part of yourself that used to play the role of wife opposite your husband (see Rando 1991: 28), which entails other significant changes. The three narratives discussed here point out that not only are the widowed single and lonely, they also stop being, at least for a time, life companions, most significantly conversational peers and lovers, a blow that might be harder to bear with age (all three writers were in their late sixties when they lost their spouses). Analogically, the loss of a spouse always means the end of a certain routine within which the deceased also played various parts, for instance, of a sexual partner, companion, accountant, baby minder, cook, gardener, intellectual equal, and so on. Becoming a widow also means learning problem solution on one's own (Parkes and Prigerson 2010: 107-108). While still in the midst of acute grief, the widow often needs to evaluate her financial situation and accommodation needs, to make decisions about simple things, such as how much food to cook for dinner for just one person, and more difficult ones, such as who to hire to repair the roof. All these changes are emotionally and physically draining for the grieving self, and it may take more than a while before the widow feels safe in her new role (Parkes and Prigerson 2010: 107; Rando 1991: 133-135).

Apart from having to cope with the experience of grief and reconfiguration of everyday roles, the widow has to face the social preconceptions of widowhood, which, more often than not, are rather unfavourable. According to various bereavement studies carried out at different time periods for over a century, most widows in Western cultures discover "that people who were previously friendly and approachable become embarrassed and strained in their presence. It is as if the widow has become tainted with death" (Parkes and Prigerson 2010: 9-10). 
A 1936 article "A little widow is a dangerous thing" describes certain cultures in British Columbia and in the Philippines which place an even stronger taboo on the bereaved, especially widows, who are secluded, forbidden to touch their own bodies, and can leave their dwelling only at an hour when they are unlikely to meet anyone, for whoever sees them is bound to die a sudden death (qtd. in Parkes and Prigerson 2010: 10). Western societies may be less direct in ostracizing widows, but the process of reconnecting the widowed self to the outside world is not easily facilitated here either. In her 1977 review essay, assessing the situation of American widows in their sixties, Carol J. Barrett writes: "There are almost 10 million widowed women in this country, constituting almost 5 per cent of the total population (...). As a minority group they suffer from sexism, ageism, and, in some cases, racism. All of them suffer because they are perceived to be carriers and transmitters of the reality of death" (1977: 856). Reviewing the cultural position of younger and older widows, Sarah Gamble concedes that contemporary culture does not promote a much improved image of the widow, who is usually located in her domestic environment, "no matter what her role outside it" (2009: 80). Examining a 2006 photograph "Widow in her kitchen" by Ikuko Tsuchiya, the winner of a minor competition reprinted in the Observer Food Magazine, Gamble observes that the author perpetuates "many of the stereotypes surrounding the cultural perception of the bereaved woman" (2009: 79). The photographer's commentary sounds equally clichéd: "Mrs Hobbs is now living alone after her husband died last year. For her, cooking is one of the most important aspects of the healing process. So I wanted to create an image about the relationship between Mrs. Hobbs and food preparation" (qtd. in Gamble 2009: 79). Gamble points out that literature and feminism have also done little for the widow so far. "Is this the postfeminist backlash at work," Gamble wonders, "or could it be that feminism has simply never formulated a revitalized definition of widowhood?" (2009: 80).

The three memoirists discussed here defy the culturally sanctioned concepts of widowhood. Didion, Roiphe, and Oates may strongly experience the absence of their spouses, stay at home for extended periods of time (especially Oates), and miss certain aspects of domesticity, but their bereavement records rediscover and reshape the image of the widow by stressing the importance of the self and its reluctance, as well as need, to readjust to the new role, which is hard enough without society making it even more of a challenge. The cultural ostracism of the widow, who, for many, becomes the embodiment of deprivation and mortality, is what all three memoirists implicitly criticize in their accounts.

Early in her narrative, Anne Roiphe informs us that "this book is about [the remaking of life]" and then adds: "I am going out on a date" (2008: 4). This is the first of many dates she describes, often with an impeccable eye for detail and comical touch, yet none of the men she meets lives up to what she had with her 
husband. While Roiphe is more than accommodating and open-minded in her approach to dating, and really wants to meet someone who would at least fulfil her sexual needs, she quickly finds out that adjusting to widowhood is more challenging than she initially expected. Within everyday routine, Roiphe's husband, Herman, performed, among many others, the role of cook and, as it turns out, irreplaceable conversational peer:

\begin{abstract}
H. returned home from his office around seven each evening. I would stand at my window on the fourteenth floor and watch him walking down the street (...). He was coming toward me. He would have his drink and we would talk (...). We talked in shorthand, whole paragraphs were left out but understood (...). Then he would fix dinner. I stood at his elbow while he chopped or stirred. Now I don't know when it's time to eat. I don't know what to eat. The day has no appointed end. It drifts off into the night. (Roiphe 2008: 14-15).
\end{abstract}

While remembering how she argued with her husband over removing the old wallpaper from their bedroom, Roiphe thinks about Charlotte Perkins Gilman's "The Yellow Wallpaper" and ponders how her own early feminist identity was quickly modified by the fact that she has "always thought of men as the necessary other" (2008: 17):

["The Yellow Wallpaper"] is a story about how men impose literal and symbolic immobility (...). True, I said, dear Charlotte Perkins Gilman, true. I had been an early feminist (...). But I always had a tendency to wander from the political line (...). I admit to a desire, lifelong, to put my hand in a man's hand and let him lead me through the thicket of taxes and insurance and such (...). Still drifting, avoiding memories, sitting on my bed and not moving, finding it hard to go to the store and buy the barest of necessities, I was aware that in this widowhood I could use a sharp infusion of feminist pride, a sense of my own power, a disinterest in attachment, a venturesome soul daring to walk my own path. (2008: 17)

In life, even in the course of one day, we shift through many different identities. Identities, Smith and Watson remind us, are "provisional," they are not "essential - born, inherited, or natural," they are not "given and fixed" (2001:33). At work one may be an understanding teacher, whereas at home $\mathrm{s} /$ he may become a frustrated mother/father, failed yet passionate painter, and/or cross-dressing marathon aficionado. As a result, there is always "the potential for conflict between or among these different identities" (Smith and Watson 2001: 33), and, depending on what cultural interactions we find ourselves in, the conflict may vary in durability and prominence. What Roiphe and many other widowed women face is the multiple identity changes and secondary identity losses resulting from their primary loss - a state that requires not only social adjustment but a significant amount of emotional and physical effort on the part of the bereaved self to reconfigure the remaining identities and fit the widowed part within this new structure. 
The conflict among identities in this freshly-created construct may last for a while or forever, depending on the bereaved self's ability to adapt as well as on how social discourses enable such adaptation.

As previously mentioned, the state of widowhood influences not only one's personal life but one's social self as well. During their mourning period, all three writers received substantial support from family and friends. At the same time all of them realize that they inhabit two worlds - the world of everyday tasks and people who attempt to help, and the world of the widowed where no one who has had little or no experience with grief dares enter, either because they do not know how or are unwilling to. Didion observes that recently bereaved people "have a certain look, recognizable maybe only to those who have seen that look on their own faces" ([2005] 2007: 74). It is a look "of extreme vulnerability, nakedness, openness," making one feel like an invisible spirit, a ghost (Didion [2005] 2007: 74-75). "I myself felt invisible for a period of time, incorporeal," Didion muses, "I seemed to have crossed one of those legendary rivers that divide the living from the dead, entered a place in which I could be seen only by those who were themselves recently bereaved" ([2005] 2007: 75). In Roiphe's experience, the widow often feels incorporeal even among her closest relatives. At dinner in her "stepdaughter J.'s home," the family talks about "science projects, (...) college applications, debate societies," which suddenly makes Roiphe feel out of place: "I am welcome but irrelevant to the evening (...). I lean back in my chair as if I were a ghost not fully visible" (2008: 55).

Likewise, Oates remembers that even after the most intense period of her despair was over, she continued to feel as if she was living in "the bell jar of the widow's slow-suffocating life outside "the real world" ([2011] 2012: 289). Her close friends look out for Oates, but some of her colleagues at the university fail to keep the Widow's social self alive, promising "phantom dinners" that never materialize (Oates [2011] 2012: 180-181). The Widow is usually more composed than Joyce because that is what society expects from her ([2011] 2012: 147). Yet, Oates constantly rebels against the state of widowhood. "I don't want to be a widow! Not me," she exclaims at one point ([2011] 2012: 147). She resists the personal, social, and temporal changes: "The widow doesn't want change. The widow wants the world - time - to have ended" ([2011] 2012: 275). Gradually, the persona of the Widow attaches herself to the despairing Joyce, who, nevertheless, continues to object to the transformation and states: "So long as (...). I can impersonate 'Joyce Carol Oates' [the writer], it is not the case that I am dead and done for-yet" (171). At one point, Oates perceives the state of bereavement as an illness, in which case, by analogy, the widow acts as a patient who needs to get over her affliction. Oates's subjective opinion parallels a general observation in Barrett's essay: "Most widows hate the word 'widow.' Many have told me that people respond to them as if they have an infectious disease" (1977: 856). 
Among the three memoirists, Oates voices the harshness of the widowed state most prominently. She is the most self-involved and self-pitying of the three widows, yet she also does the most to formulate a new definition of widowhood as well as reintroduce and reposition the widow in culture and literature. She even pronounces her new self in the title of her narrative: A Widow's Story: A Memoir, incorporating this rather undesirable identity into the matrix of culturally endorsed identities. According to Oates, the current role of the widow in society is non-existent: "the widow speaks a language others can't understand. Like the aptly named black widow spider, the (human) widow is best avoided" ([2011] 2012: 325). Oates's memoir features multiple definitions of this outcast identity, leaving no doubt that one of the writer's aims is to teach the language of the widow to readers and critics. With the current outpour of grief memoirs, a majority of them by women, one hopes for some changes in Western mourning practices, or at least for more accessibility and interest in the taboo language of the bereaved, especially widows.

As far as the bereaved self is concerned, even though the three writers discuss mostly the downsides of this new identity, they also learn to live with it and represent it comprehensively in their accounts that enter society and culture via readership. Unlike "Widow in her kitchen," Didion, Roiphe, and Oates see the domestic as a safe place to grieve undisturbed, but they need much more than cooking or cleaning to adapt to widowhood. While all three memoirists are undoubtedly disturbed by the absence of a significant other, contrary to traditional assumptions, they refuse to "survive in a shadowy existence" and can conceive of a new identity for themselves which, while still pointing to their husband's absence, is significant because the self tests and adjusts to it at her own pace (cf. Gamble 2009: 79). A widow may be an outcast, a culturally available model of identity that no one really wants to adopt or reproduce; yet, she also reminds others of the commonality of death, loss, and loneliness, struggling to evoke understanding devoid of condescension and pity. As Smith and Watson point out, "identity as difference implies identity as likeness" (33). No matter how reluctant we are to acknowledge it, we all share some common ground with the widow. The loss of a significant life companion befalls, after all, not only aging women who enjoy domestic chores, regardless of how "other" they seem to others.

\section{The adjusting power of writing}

Grieving may take weeks, months, or even years. When one survives the period of acute grief, a certain level of adjustment and acceptance is necessary to go on. In the case of the discussed memoirists, two aspects of adaptation stand out: writing one's grief away and, as Didion puts it, "the question of self-pity" ([2005] 2007: 3). Self-making is to a large degree a narrative act (Bruner 1994: 41-53 and 
Polkinghorne 1991: 135-153). "Under stressful conditions, a self-narrative may decompose," and writing, very much like the talking cure, helps reconstruct "a meaning-giving narrative of self-identity" (Polkinghorne 1991: 135; see also: Frank 1995: 53-53, 64-68). For Didion, Roiphe, and Oates, writing their memoirs becomes part of their grieving process, a way to find themselves in the confusion of grief, to observe if the self that once was still has a voice. In the opening pages, Didion states that the memoir is her "attempt to make sense of the period that followed" the loss, of "weeks and then months that cut loose any fixed idea [she] had about death, (...) about marriage (...), about grief, about the ways in which people do and do not deal with the fact that life ends, about the shallowness of sanity" ([2005] 2007: 7). With her assumptive world in ruins, a new one is being constructed in the memoir. At the end of her account, Didion admits that she does not want to finish writing it ([2005] 2007: 224), very much like she does not want her year of magical thinking to end. While she is disappointed no clear resolution to her situation has been found, Didion also realizes that bringing the book to an end forces her to see that it was, in fact, a year without John, that soon enough her sense of him alive "will become more remote, (...) transmuted into whatever best serves [her] life without [him]" ([2005] 2007: 224-225). Didion did not start writing her account until almost ten months after her husband's death, during which time their daughter Quintana, who suffered and partially recovered from pneumonia and septic shock, collapsed after getting off a plane in California and had to undergo emergency brain surgery at UCLA, where Didion ended up spending a lot of time ([2005] 2007: 89-90, 99). Eighteen months after John's death, Quintana died of acute pancreatitis at the age of thirty-nine, which prompted Didion to write Blue nights, another bereavement memoir in which the writer faces the new loss and grief in an even more head-on manner. When asked how she managed to write against the background of the first loss and all the fear connected with Quintana's hospitalizations and failing health, Didion admits that writing helped her realize that she was indeed to a certain extent going crazy with grief, which, in a way, was a good thing because at least she knew she was still capable of cognitive functioning in the world (Brockes 2005). "Well there was nothing else to do," she states, "I had to write my way out of it. Because I couldn't figure out what was going on" (Brockes 2005).

Roiphe believes writing about oneself is always contaminated "by the act of observing," but she also asserts its importance in sustaining her self through the turmoil of bereavement:

Writing this book provides a floor under my experience. Having used writing to hold myself erect all my adult life, I am bold enough to believe that I cannot fall because of this word scaffolding that, all invisible, props up my days. Perhaps I am wrong. Perhaps the fact of writing a book is not so life-saving as it seems. But it 
was necessary to acknowledge the fact of the book I am writing as I am living because without the book that I am writing which is the one that you are reading I would be a sorrier woman, a shell of a woman, lingering on. (Roiphe 2008: 21-22)

While Oates has problems focusing on her creative work during her bereavement (388), she continues to write diary entries and emails to friends, documenting the process from the very beginning, which amounts to a 415-page book - living proof that, like Didion and Roiphe, she needed to write her way out of grief. In an email to her good friend Edmund White, barely three days after Ray's death, the hurting and panic-stricken writer admits that "just typing this letter is satisfying somehow" (Oates [2011] 2012: 115). "We are addicted to language for its sanity-providing," she concludes (Oates [2011] 2012: 115).

For Mrs Hobbs, her kitchen and cooking might have been "one of the most important aspects of the healing process" (see Gamble 2009: 79), but most widows, especially in contemporary culture, explore other mourning practices as well. As life writing is not limited to published accounts, especially in the case of traumatic life events, many widows keep diaries and are encouraged by friends and clinicians to express their emotional turmoil and memories of the dead in written form. It has been discussed here how important relationality is for the self's well-being, which, supported by various experts, proves the inadequacy and unnaturalness of fierce self-reliance. "Recognition [by the other] is so central to human existence, as to often escape notice," states Jessica Benjamin, "or, rather, it appears to us in so many guises that it is seldom grasped as one overarching concept. There are any number of near-synonyms for it: to recognize is to affirm, validate, acknowledge, know, accept, understand, empathize, take in, tolerate, appreciate, see, identify with, find familiar,... love" (1988: 15-16). With the loss of a beloved life partner, all these aspects of recognition become severely tested. As Katherine Ashenburg points out, "[e]ven well-intentioned family and friends may become impatient or bored or frustrated with the trajectory of grief" (2009: 164) and temporarily strip the bereaved of necessary support. Writing, however, does not. The act of narrating steadily keeps the mourner company in her loneliness and, as a published account, provides company for other bereaved selves who seek understanding and help in available cultural discourses.

\section{Conclusion}

Narrating grief is possibly one of the most lonely, self-absorbed forms of life writing. Psychological research proves that "loneliness presents a threat to a person's integrity and well-being, to the very sense of who one is" (Scarf 2008). In his classic medical study on loneliness, James L. Lynch observes: "The sudden loss of a loved one abruptly removes human companionship and a source of love 
from one's life. Loneliness and grief often overwhelm bereaved individuals, and the toll taken on the heart can be clearly seen. As the mortality statistics indicate, (...) people do indeed die of broken hearts" (1977: 56). Loneliness makes up a large part of a newly widowed woman's life, increasing the need to share this unbearable feeling with others, in the case of grief memoirists with a wider audience. In the three accounts discussed here, the readjusting bereaved selves reflect on the loss of self with the death of a beloved spouse, their self-altering grief experience, and the state of widowhood, voicing the modern shift away from the monadic, Freudian model of the self and "the myth of rugged individualism" toward the relational model supported by various theoretical backgrounds. Joan Didion, Joyce Carol Oates, and Anne Roiphe authenticate the widow's experience by their individual, eloquent records that, nevertheless, share a lot of common ground with each other and substantiate modern grief research, challenging those sceptical autobiography critics who question life writing as a credible literary genre.

\section{REFERENCES}

\section{PRIMARY SOURCES}

Didion, Joan. [2005] 2007. The Year of Magical Thinking. New York: Vintage. Oates, Joyce Carol. [2011] 2012. A Widow's Story: A Memoir. London: Fourth Estate. Roiphe, Anne. 2008. Epilogue: A Memoir. New York: Harper.

\section{SECONDARY SOURCES}

Ashenburg, Katherine. 2009 The mourner's dance: What we do when people die. Toronto: Vintage. Barnes, Julian. 2011. For sorrow there is no remedy: A Widow's Story: A Memoir. New York Review of Books, Apr. 7, 2011. http://www.nybooks.com/articles/archives/2011/apr/07/sorrow-there-no-remedy/, (accessed 20 October 2014).

Barrett, Carol J. 1977. Women in widowhood. Signs 2(4), 856-868.

Benjamin, Jessica. 1988. The bonds of love: Psychoanalysis, feminism, and the problem of domination. New York: Pantheon Books.

Berman, Jeffrey. 2010. Companionship in grief: Love and loss in the memoirs of C. S, Lewis, John Bayley, Donald Hall, Joan Didion, and Calvin Trillin. Amherst \& Boston: University of Massachusetts Press.

Bowlby, John. [1969] 1982. Attachment and loss. Volume I Attachment. $2^{\text {nd }}$ edn. New York: Basic Books.

Brockes, Emma. 2005. Interview with Joan Didion. Guardian, Dec. 16, 2005. http://www.theguardian.com/film/2005/dec/16/biography.features, (accessed 15 October 2014). 
Bruner, Jerome. 1994. The 'remembered' self. In Ulric Neisser \& Robyn Fivush (eds.), The remembering self: Construction and accuracy in the self-narrative. 41-54. Cambridge: Cambridge University Press.

Cross, Stephenie. 2011. The books interview: Joan Didion. New Statesman (1996) 140 (5078), 49.

Eakin, Paul John. 1999. How our lives become stories: Making selves. Ithaca: Cornell University Press.

Frank, Arthur W. 1995. The wounded storyteller: Body, illness, and ethics. Chicago: University of Chicago Press.

Freud, Sigmund. [1917] 1968. Mourning and melancholia. In James Strachey (ed. \& trans.), The standard edition of the complete psychological works of Sigmund Freud: On the history of the psycho-analytic movement, papers on metapsychology and other works, vol. XIV, 1914-1916, 237-258. London: Hogarth Press and the Institute of Psycho-analysis.

Freud, Sigmund. [1918] 2009. Totem and taboo. New York: Cosimo.

Gamble, Sarah. 2009. The Husbandless home: Domesticity and the young widow in the contemporary novel. In Stacy Gillis \& Joanne Hollows. Feminism, domesticity and popular culture. 79-92. New York: Routledge.

Klass, Dennis, Phyllis R. Silverman \& Steven L. Nickman. 1996. Continuing bonds: New understanding of grief. New York: Routledge.

Krakauer, Jon. 2013. How Chris McCandless died. New Yorker: Newyorker.com, Sep. 12, 2013. http://www.newyorker.com/books/page-turner/how-chris-mccandless-died (accessed 15 September 2015)

Kübler-Ross, Elisabeth \& David Kessler. 2007. On grief and grieving: Finding the meaning of grief through the five stages of loss. New York: Scribner.

Lynch, James J. 1977. The broken heart: The medical consequences of loneliness. New York: Basic Books.

Parkes, Colin Murray \& Holly G. Prigerson. 2010. Bereavement: Studies of grief in adult life. $4^{\text {th }}$ edn. London: Penguin.

Polkinghorne, Donald E. 1991. Narrative and self-concept. Journal of Narrative and Life History 1 ( 2 \& 3), 135-153.

Rando, Therese A. 1991. How to go on living when someone you love dies. New York: Bantam.

Raphael, Beverley. 1985. The anatomy of bereavement: A handbook for the caring professions. London: Routledge.

Scarf, Maggie. 2008. The unmerry widow: Review of Epilogue: A Memoir by Anne Roiphe. New York Times: Nytimes.com, Aug. 24, 2008.

http://www.nytimes.com/2008/08/24/books/review/Scarf-t.html?pagewanted=print, (accessed 15 October 2014).

Silverman, Phyllis R. \& Dennis Klass. 1996. Introduction: What's the problem. In Dennis Klass, Phyllis R. Silverman, \& Steven L. Nickman. Continuing bonds: New understanding of grief. 3-27. New York: Routledge.

Silverman, Phyllis R. 2005. Widow to widow: How the bereaved help one another. New York: Brunner-Routledge.

Smith, Sidonie, \& Julia Watson. 2001. Reading autobiography: A guide for interpreting life narratives. Minneapolis: University of Minnesota Press.

Stroebe, Margaret \& Henk Schut. 1999. The dual process model of coping with bereavement: Rationale and Description. Death Studies 23(3), 197-224.

Worden, Worden, J. William. (2009). Grief counseling and grief therapy: A handbook for the mental health practitioner. $4^{\text {th }}$ edn. New York: Springer. 